\title{
Cost Optimization Of Micro-Grid Of Renewable Energy Resources Connected With And Without Utility Grid
}

\author{
Dr. A. S. Kannan, Srikanth Thummala*, Dr. B. Mouli Chandra \\ Associate Professor, *Research Scholar, Professor, \\ Department of Electrical Engineering, Annamalai University, Tamilnadu, India \\ EEE, QIS College of Engg. \& Technology, Ongole, Andhra pradesh.
}

Article History: Received:11 January 2021; Accepted: 27 February 2021; Published online: 5 April 2021

\begin{abstract}
Arranging and enhancement of small-scale lattices in determined zone examined in this paper miniaturized scale framework is associated with and without grid to meet the load profiles, particular micro grid arrangements with age from sustainable power sources are developed. Better examinations are then conveyed utilizing HOMER vitality programming to decide cost of economy, measuring, and locating and framework designs. Micro grid is likewise associated with the network because of shortage of supported sustainable power sources. This paper shows a short differentiate among the assorted cost types of gear, control the board and launches for every one of the setups. The improvement result shows the most reduced expense per unit and it allots the positioning for every framework.
\end{abstract}

Keywords: Micro Grid, Renewable Energy Resources, HOMER-Hybrid Optimization of Multiple Energy Resources.

\section{INTRODUCTION}

Augmentation in surge levels, utilization of fossil stores and a reliably extending enthusiasm for imperativeness has been an important stress in the last various years. These stresses have filled a speedy headway in the regions of scattered supportable power source ages. Also, to facilitate these cleaner and progressively compelling unlimited sources inside the power system sort out, scaled down scale systems presents itself to be a sensible course of action [1-5]. They have a couple of various focal points which fuses decline in transmission setbacks, improvement in impact quality and trustworthiness, decline in releases and even offers game plans to heterogeneous impact quality [6]. Furthermore, most importantly, it in like manner gives likelihood to zap of remote towns which are far from reach of the conventional system. Load profiles in India and urban regions to be consideration to the investigation. Utilizing those load profiles distinctive arrangements in micro grid systems to built and re-enacted in homer energy system [7]. Homer taken yield to the ideal network arrangement it is required for a solid system activity. The improvement result likewise given the aggregate expense and it expense of vitality for a micro grid. Right off the bat, the heap profile to a town in Nellore, India is utilized to develop a rustic ac micro grid system.

The framework comprises of vitality sources and capacity as PV cluster, wind turbine and lead corrosive batteries. At that point utilizing Homer, enhancement considers are done to accomplish a negligible expense of activity for the framework to be totally individual. After this, utilizing a similar burden, a comparative report for incomplete network to the grid is also conducted. This study is important as most part of the grid connected small town areas (especially in India). For both the cases in with connected grid or without connected grid, the micro grid framework comprised of biodiesel generators as the heaps care significantly bigger when contrasted with small town areas. Similar simulations examines are then done to recognize the optimal system configuration.

The system comprises of vitality sources and capacity as PV exhibit, wind turbine and lead corrosive batteries. At that point utilizing Homer, advancement studies are done to accomplish an insignificant expense of activity for the framework to be totally person. After this, utilizing a similar burden, a comparable report for fractional availability to the network is additionally led. This investigation is significant as most piece of the network associated community territories (particularly in India). For both the cases in with associated matrix or without associated framework, the smaller scale network framework comprised of biodiesel generators as the heaps care impressively bigger when contrasted with community regions. Comparative reproductions studies are then done to recognize the ideal framework setup.

At last, the consequence of enhancement think about demonstrates that the AC micro grid is associated with matrix and without association of network can be structured by cost contemplations. The system with lattice network, a vastly improved outcome is seen with a consistent supply of power and a critical decrease in outflows. Here, it ought to be noticed that most other accessible examination on enhancement of crossover sustainable power source framework utilizing Homer focuses upon solitary system [8-22]. While on account of these examination, with the outcomes of an extensive 
variety of framework designs for load focuses, a near report is made conceivable. Also, with such similar outcomes, a more extensive picture on the favorable position and downsides of every system type can be drawn. In addition, the investigation is led utilizing practical load profile, genuine assets information and genuine costs of segments, the result or a comparative enhancement approach can take to utilized for a real system execution

In the first section of this paper system components of a $\mathrm{AC}$ micro grids is connected to the with grid without grid and the different operations used for micro grid optimization. The following segment talks about the different parts of the small scale framework and assets that are required to show the total framework in Homer. This is followed a detailed gritty conversation on the simulation processes to obtain the optimization result. The accompanying segment gives results to every one of the miniaturized scale matrix frameworks. A detailed gritty conversation on the outcomes acquired is likewise introduced in a similar area. At last, the paper finishes up with a short note on the significance and attainability of micro grid systems.

In the first section of this paper systems parts of an AC micro grids is associated with the with grid without grid connection and the diverse activities utilized for micro grid advancement. The following segment examines the different systems of the micro grid and assets to be required to show the entire system in Homer. This is pursued a definite exchange the re-enactment procedures to get the advancement result. The accompanying segment gives result to each of the micro grid system. A point by point discourse on the outcomes got is likewise exhibited in a similar area. At last, the paper finishes up of a concise on the significance and attainability of micro grid systems.

\section{SYSTEM COMPONENTS}

In micro grid system diesel generator bio gas as a fuel, PV system, wind turbine, energy storage devices and converters to survive the loads. Microgrid systems implemented in homer software here two systems considered the fist system is without grid and the second system is with grid. According to this particular place need to take source of resources like solar irradiance and wind data, load data, especially cost of the all components in the systems. The fallowing sections are described full details all the components, resources and design of microgrid and its operation. The two systems of micro grid as shown in the figure 1.
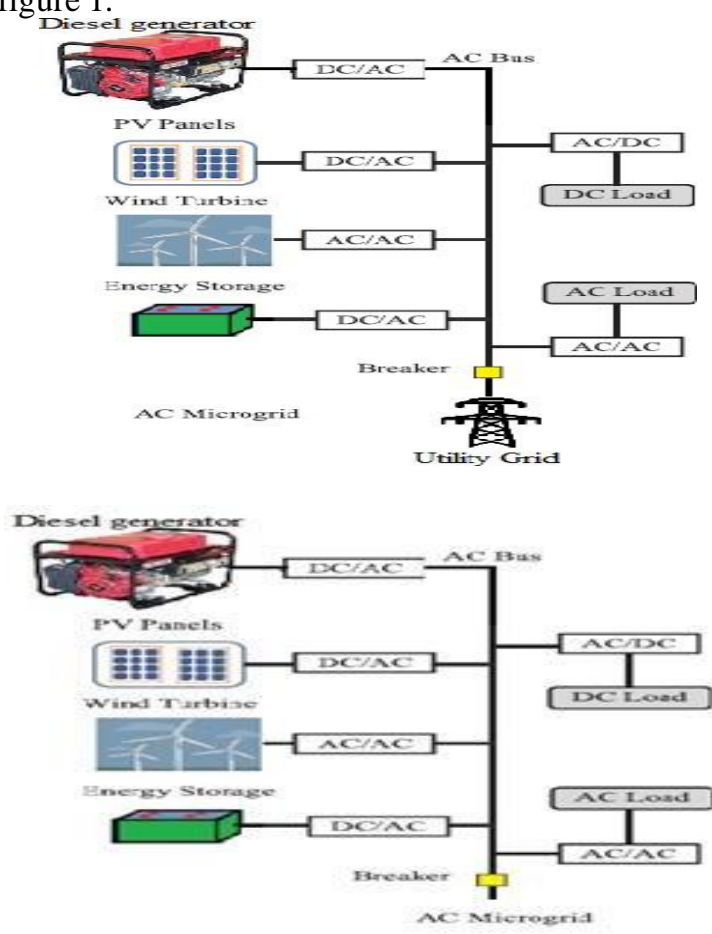

Fig. 1. Schematic diagram of AC Microgrid (a) with grid and (b) without grid

During the time spent arranging and improvement of a micro grid display utilizing Homer programming, certain essentials can be recognized. Right off the bat, the parts of the smaller scale matrix should be resolved will incorporate the different sources, burdens and converters. The sort, structure, economic cost and different properties of every one of the parts are given to contributions to these Homer models. After the parts are set, there is a need to acquire the models of assets which will comprise of hourly variety of wind speed and sun oriented radiation information. In addition, the sort 
and costs of fuel assets utilized are additionally given. Just with this arrangement of Data sources one can proceed with the reproduction and streamlining procedure of the micro grid framework. The accompanying subsection gives a point by point depiction on the general schematic of the created micro grid, every one of the parts and assets inputs required for the reproduction procedure.

\section{OVERALL SCHEMATIC}

The general frame work of the micro grid with its different parts is shown beneath in Fig. 2. It comprises of spiral AC transport to every one of the parts are associated. As far as sustainable power source age a variety of photovoltaic modules and Wind Turbines are considered in the framework. Bio Diesel Generators (DG) filled by diesel is additionally taken as hotspot for a portion to the designs. Yield to the different sources is associated with the DC transport through legitimate converters. The heaps of framework can change to be household and business stack which can have a place with either a provincial or an urban territory. These heaps can to be further sub delegated essential and secondary stacks as appeared shows in figure. As the inexhaustible sources are discontinuous in nature and the micro grid framework is considered to work self-ruling, vitality stockpiling turns into a significant segment. What's more, thus, vitality stockpiling as lead corrosive batteries are considered.
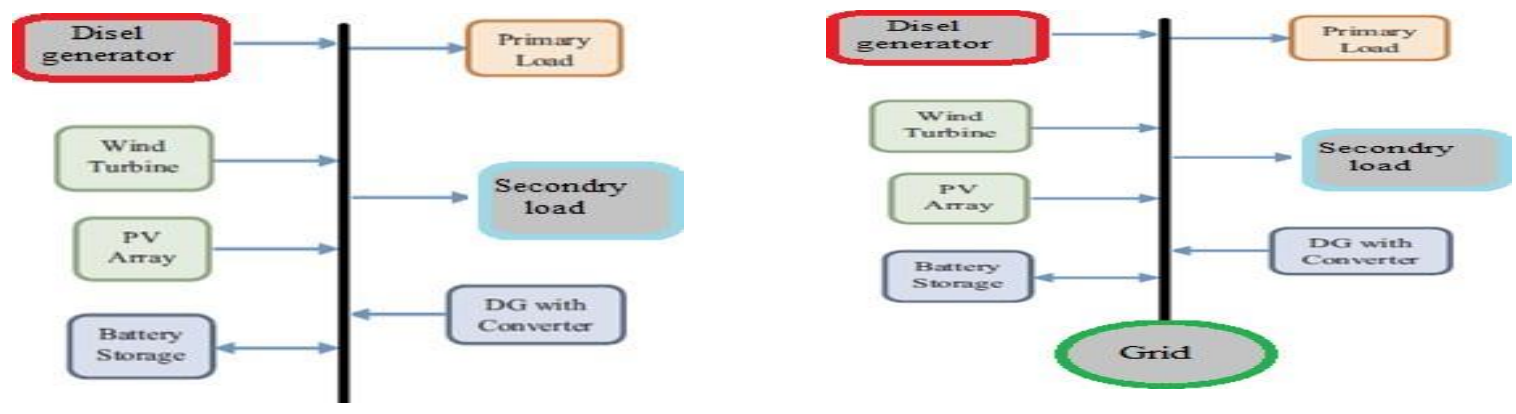

Fig. 2. Structure model of the developed micro grid with all its components (a) with grid (b) without grid

\subsection{LOAD PROFILE}

Homer shows hourly estimations as one of load profile of its information sources. In this investigation, two load profiles are taken as considered. The principal stack profile is that of a town which is illustrative of rustic situation. The second one is a urban building or a network. Here as shown in the above figures load profiles of hourly, monthly, yearly data primary and secondary loads with a an average load of $11.26 \mathrm{kWh} /$ day.
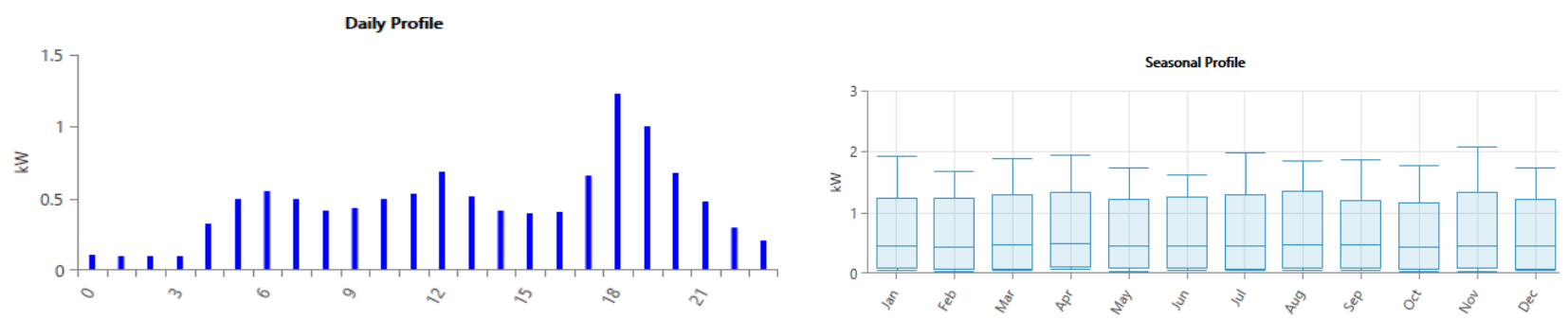

(a)

(b)

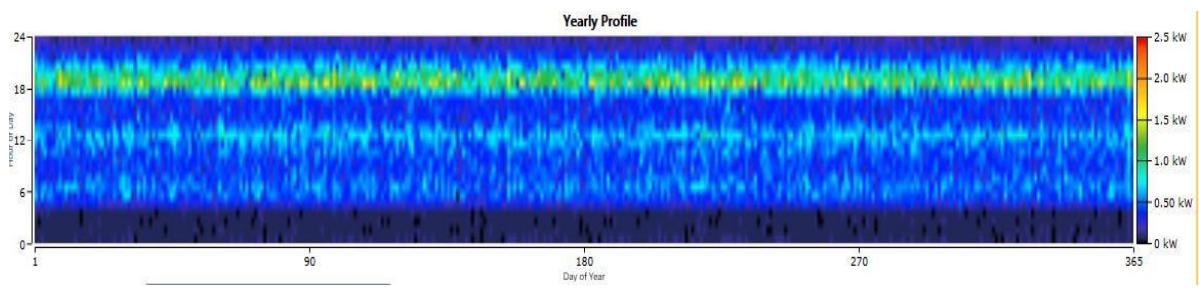

(c)

Fig. 3. Average load profile of primary load 1and 2 for Nellore (a) hourly (b) monthly(c) yearly 


\subsection{ENERGY GENERATION AND ITS STORAGE COMPONENTS}

\subsubsection{Photovoltaic generation}

A conventional level plate type PV (Photovoltaic) board is considered for this investigation. The lifetime of the PV boards is considered as 20 years and the power output rating is $1 \mathrm{~kW}$ with a derating factor is considered at $80 \%$. The photovoltaic (PV) derating factor is a scaling factor that HOMER applies to the PV exhibit power yield to represent diminished yield in genuine working conditions contrasted with the conditions under which the PV board was appraised. Utilize the derating component to represent such factors as ruining of the boards, wiring misfortunes, concealing, snow spread, maturing, etc.

$$
P_{P V}=Y_{P V} F_{P V}\left(\frac{G_{T}}{G_{T, S T C}}\right)\left[1+\propto_{p}\left[T_{C}-T_{C, S T C}\right]\right] \ldots
$$

Where, $Y P V$ is the rated capacity of the $\mathrm{PV}$ in $\mathrm{kW}, f P V$ is the $\mathrm{PV}$ derating factor, $G T$ is the solar radiation incident on the $\mathrm{PV}$ array in $\mathrm{kW} / \mathrm{m} 2, G T, S T C$ is the incident radiation at standard test conditions $(1 \mathrm{~kW} / \mathrm{m} 2), \propto_{p}$ is the temperature coefficient of power $\left(\% /{ }^{\circ} \mathrm{C}\right), T C$ is the PV cell temperature in ${ }^{\circ} \mathrm{C}, T C, S T C$ is the PV cell temperature under standard test conditions $\left(25^{\circ} \mathrm{C}\right)$.

We can see that the capital cost of PV generation is further subdivided into three parts. The prices mentioned are the actual prices incurred while designing a laboratory setup of a DC micro grid at the Electrical Engineering, JNTU HYD, and India. Cost components and the breakdown of capital cost for PV generation capital cost is $3000 \$$, replacement cost is $2900 \$$ and operating \& maintenance cost is $10 \$$ per $1 \mathrm{Kw}$.

\subsubsection{Wind turbine generation}

A model of generic $3 \mathrm{~kW}$ wind turbine which is already available in HOMER library is used for modelling the generation from wind energy. The power curve of the WT is given in Fig. 4. Using this power curve, the output of the WT is calculated in a three-step process. The capital, replacement and operation \& maintenance cost of the WT are taken as $18,000 \$ / \mathrm{kW}, 17,500 \$ / \mathrm{kW}$ and $180 \$ / \mathrm{kW} /$ year respectively. The various cost components that makes up the capital cost includes the cost of turbine rotor, tower, control system, wiring and installation. Here, the lifetime of the wind turbine is considered as 20 years and hub height is $17 \mathrm{~m}$.

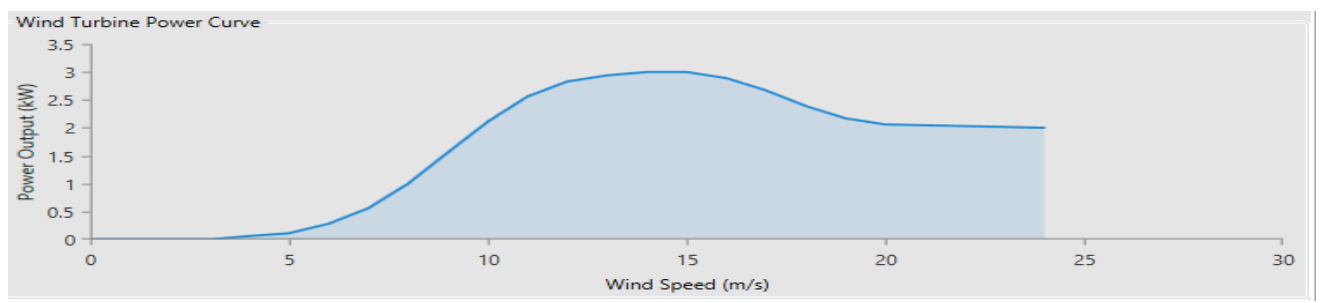

Fig.4 Power curve of the generic $3 \mathrm{~kW}$ wind turbine

\subsubsection{Battery energy storage}

A model of nonexclusive $1 \mathrm{~kW}$ h lead corrosive battery is utilized for displaying the vitality stockpiling unit. This specific sort of battery is picked because of its moderately great exhibition and minimal effort. The different properties of the battery are given in Table 5. Subsequent to considering a portion of the famous battery producing brands in India, the capital expense of a $1 \mathrm{~kW} \mathrm{~h}$ lead corrosive battery is taken as $154 \$$. This incorporates the battery mounting unit, establishment and wiring costs. The substitution cost is accepted same as the capital while the activity and support cost is taken as $15.4 \$ / \mathrm{kW}$ h/year.

\subsubsection{Diesel generator}

In a portion of the reenactment work completed in this paper, age from diesel generators are likewise thought of. The major physical properties of a generator are the most extreme and least electrical force yield, lifetime in number of working hours, the fuel type, and its fuel bend, which gives the connection between amounts of fuel devoured to electrical force delivered [16]. The fuel bend is expected as a straight line with a y block which is given by the accompanying condition for fuel utilization: 


$$
F=F_{0} Y_{G e n}+F_{1} P_{G}
$$

Where, $F 0$ is the fuel curve intercept coefficient, $F 1$ is the fuel curve slope, $Y g e n$ is the rated capacity of the generator in $\mathrm{kW}$ and $P g e n$ is the electrical output of the generator in $\mathrm{kW}$.

A conventional $500 \mathrm{~kW}$ gen set which is promptly accessible in Homer assets library is utilized for this reason. The lifetime of the generator is considered as $15,000 \mathrm{~h}$. The capital and substitution cost is taken as $385 \$$ per $\mathrm{kW}$ of the generator evaluations. While the activity and upkeep cost of the generator unit per $\mathrm{kW}$ is taken as $0.15 \$ / \mathrm{h}$. Other than these information sources, the costs of the fuel are examined in the following area. As the generator yield is as air conditioning, converters are expected to associate it to the DC miniaturized scale framework arrange. Here a nonexclusive converter is considered for demonstrating in Homer. As the progression of intensity back to the matrix isn't considered in this examination, the essential capacity of the converter is to redress the air conditioner yield to dc. Furthermore, subsequently the costs of the converter are additionally similarly lesser when contrasted with a bidirectional converter. Here, for this examination, after a decent measure of study on the Indian markets, the capital expense of the converter is considered as $154 \$$ per $\mathrm{kW}$. The lifetime and effectiveness of the converter is considered as 15 years and $90 \%$ respectively.

\subsection{RESOURCES DATA}

Assets to be depicted of anything to originate from outside of the micro grid framework and this is utilized by the framework to produce electrical power. The inexhaustible assets can change massively with area. The sort and nature of accessible asset impacts the conduct and financial aspects of the micro grid framework, since they decide the amount and timing of intensity generation. What's more, subsequently a watchful choice or displaying of sustainable asset information is a fundamental component for the general recreation and streamlining process. Assets information as sun powered light, wind speed and fuel costs are taken as one of the contributions for the recreation procedure in Homer. With the end goal to create reasonable displaying consequences of the planned micro grid, wind speed and sun oriented light information are acquired from the National Renewable Energy database. For a given territory in the Indian subcontinent, the dataset 3 hourly estimations of climate information for the era of 2011-2017. A year from this dataset is picked and is given as a contribution to Homer. For this examination, the information of sun powered Global Horizontal Irradiance (GHI) is acquired for the zone of Nellore. The normal day by day illumination for every one of the month during the time is given in Fig. 4. The clearness list for every one of the month is additionally given in a similar figure. Here clearness record is a proportion of clearness of the environment. It is the bit of the additional earthbound sunlight based radiation that achieves the earth surface. For wind speed information, Indian city of Nellore in Andhra Pradesh is considered. At long last, the kind of fuel for use in the diesel generator is likewise given as an asset contribution for the reenactment. Here, rather than typical diesel, biodiesel is taken as a fuel of decision. Despite the fact that it has a lower warming quality $(38.50 \mathrm{MJ} / \mathrm{kg})$ than that of typical diesel, it produces lesser discharges. The costs of the biodiesel are considered as $0.53 \$$ per liter which is additionally impressively lower than typical diesel costs

\section{MICROGRID SIMULATION AND OPTIMIZATION}

Recreation of the small scale lattice framework is completed in Homer to anticipate the ideal framework setup. The reenactment procedure models the presentation of a framework design to decide its specialized plausibility and life-cycle cost. Once more, the improvement procedure reenacts a wide range of framework designs looking for one which fulfills the specialized limitations at the most minimal life cycle cost. For this investigation, contingent upon the sort of burden, parts of the microgrid framework are picked appropriately. It is to be noticed that the choice of sustainable power source age simply relies upon the accessibility of the comparing assets in the territory. After this, appropriate contributions of wind speed information, sun oriented light information and fuel costs are likewise given. Homer likewise acknowledges a scope of contributions to terms of the limit of every age, stockpiling units, fuel costs and so on. Also, from inside the predefined limit, Homer chooses the ideal size of every one of the parts. The last reenactment result yields a lot of framework design which are masterminded arranged by least costs of vitality. What's more, alongside this streamlining result monetary examination are additionally completed in further areas. Two of the fundamental monetary components for the enhancement procedure are the all out Net Present Cost and levelized Cost of Energy . Here, NPC (or Life Cycle Cost) of a part is the current estimation of the considerable number of expenses of introducing and working that segment over the undertaking lifetime, short the current estimation of the considerable number of incomes that it procures over the task lifetime [7]. The two components rely upon the annualized cost of the framework. The total NPC is calculated as [10]: 


$$
C_{N P C}=\frac{c_{\text {TANN }}}{C R F_{(i, N)}}
$$

Where $C T A N N$ is the total annualized cost, $\mathrm{i}$ is the actual interest rate, $\mathrm{N}$ is the number of years and $C R F(i, N)$ is the capital recovery factor which is calculated as following:

$$
C R F_{i, N}=\frac{i(1+i)^{N}}{(1+i)^{N-1}}
$$

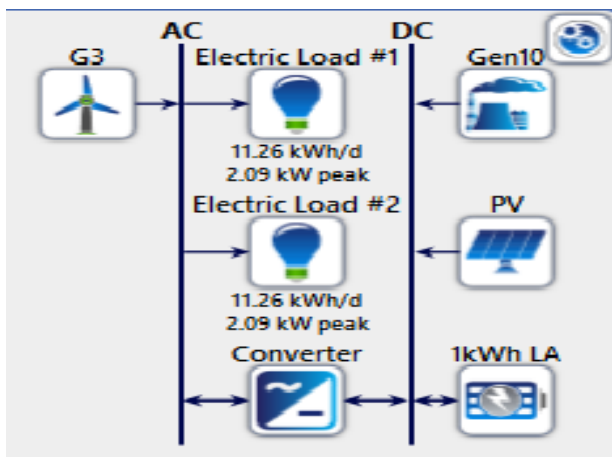

(a)

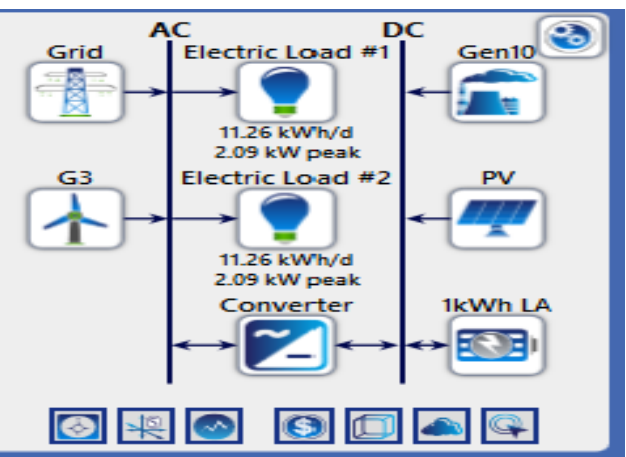

(b)

Fig 5. (a) Homer simulation diagram for without grid (b) Homer simulation diagram for with grid

\subsection{The levelized cost of energy}

$$
C O E=\frac{C_{\text {TANN }}}{E_{l s}+E_{\text {grid }}}
$$

Where, Els is the electrical energy that is supplied by the micro grid and Egrid is the amount of electricity sold by the micro grid to the main grid. Here in HOMER, the complete NPC is the financially favored component and not the levelized COE as every one of these choices is to some degree subjective.

A framework dispatch procedure is additionally established which gives a lot of rules to control the activity of the dispatch capable framework parts (generators, battery bank and so forth.). For every hour of the year, the reenactment study decides whether the inexhaustible sources (which are non dispatchable) can gracefully the heaps. In the event that the heaps can't be met, the most ideal approach to dispatch the dispatchable parts is resolved. The central rule that is followed in dispatching is minimization of cost. Furthermore, subsequently, a blend of dispatchable sources with a least working expense is in this way decided and actualized. A similar cost based dispatch rationale is utilized in all the framework arrangements. For all the reenactments, the lifetime of the task is taken to be 25 years. The accompanying subsection subtleties the reproduction techniques of the diverse micro grid setup considered for the examination.

\section{RESULTS AND DISCUSSIONS}

Simulation studies explain out for the overall and categorize results different types of micro grid. In overall results figure the system configurations all the combinations of the micro grid and it will give the rankings of each system according to the least unit price COE. Here it explains best configuration design in the list of results and detailed discussions are presented in below sections.

\subsection{SYSTEM AND COST COMPONENTS}

For the setup, Table 1 gives optimization result of the without grid connected system. The very first selection of optimized result consists of a system with $6.22 \mathrm{~kW}$ of PV, Ten $10 \mathrm{~kW}$ generators and there is no requirement of wind turbines and $31 \mathrm{~kW} \mathrm{~h}$ of battery (LA) and $3.73 \mathrm{~kW}$ converters. The cost of energy was calculated to be $0.627 \$$ per unit of electricity. The system is configured PV $6.22 \mathrm{~kW}$, one wind turbine $3 \mathrm{Kw}$, Generators $10,31 \mathrm{~kW}$ h of Battery (LA), and $3.73 \mathrm{~kW}$ Converter per unit. The cost of economy (COE) is $\$ 0.790$.

The optimization results of with grid connected system are presented in table2. In this the fist system is regarding to grid is connected to load only and ,PV, wind turbine, generator, battery, and converters are absent here due to because of grid connected system is reliable. The system COE is $\$ 0.100$ per unit when compared previous systems then net present cost NPC is low. The second system 
is the combination PV and grid is to meet the load and COE is $\$ 0.200$ even COE is high when compared to grid connected system we will have to develop the renewable energy sources in future conventional energy sources are running out in early

Table 1 system design and cost components for without grid connection

\begin{tabular}{|l|l|l|l|l|l|l|l|l|}
\hline \multicolumn{9}{|l|}{ System design } \\
\hline $\begin{array}{l}\text { PV } \\
\mathrm{kW}\end{array}$ & $\begin{array}{l}\text { Wind } \\
\text { Turbine } \\
\text { G3 kW }\end{array}$ & $\begin{array}{l}\text { Diesel } \\
\text { Generator }\end{array}$ & $\begin{array}{l}\text { Battery } \\
1 \mathrm{kWhLA}\end{array}$ & $\begin{array}{l}\text { Converter } \\
\mathrm{kW}\end{array}$ & COE & NPC & $\begin{array}{l}\text { Operating } \\
\text { cost }\end{array}$ & $\begin{array}{l}\text { Initial } \\
\text { cost }\end{array}$ \\
\hline 6.22 & 0 & 10 & 31 & 3.73 & $\$ 0.627$ & $\$ 66,565$ & $\$ 2,512$ & $\$ 34,090$ \\
\hline 5.65 & 1 & 10 & 31 & 3.73 & $\$ 0.790$ & $\$ 83,923$ & $\$ 2,594$ & $\$ 50,387$ \\
\hline
\end{tabular}

Table 2 system design and cost components for with grid connection

\begin{tabular}{|c|c|c|c|c|c|c|c|c|}
\hline \multicolumn{5}{|c|}{ System design } & \multicolumn{4}{|l|}{$\operatorname{cost}$} \\
\hline PV kW & $\begin{array}{l}\text { Wind } \\
\text { Turbine } \\
\text { G3 kW }\end{array}$ & $\begin{array}{l}\text { Diesel } \\
\text { Generator }\end{array}$ & $\begin{array}{l}\text { Grid } \\
\mathrm{kW}\end{array}$ & $\begin{array}{l}\text { Converter } \\
\mathrm{kW}\end{array}$ & $\mathrm{COE}$ & NPC & $\begin{array}{l}\text { Operating } \\
\text { cost }\end{array}$ & $\begin{array}{l}\text { Initial } \\
\text { cost }\end{array}$ \\
\hline 0 & 0 & 0 & 999,999 & 0 & $\$ 0.100$ & $\$ 10,624$ & $\$ 821.82$ & 0 \\
\hline 0.00596 & 0 & 0 & 999,999 & 0 & $\$ 0.200$ & $\$ 10,633$ & $\$ 821.01$ & $\$ 19.31$ \\
\hline
\end{tabular}

\subsection{ELECTRICAL ENERGY PRODUCTION}

The electrical energy production is shown in fig 6 without connection of grid and with connection of grid the PV generation high when compared to generator and the majority load demand is supplied by using PV is shown in fig 6(a). In the grid connected system overall load demand is supplying by the grid connection shown in fig 6(b). Fig 7 shows energy purchased from the grid.

Fig. 8 shows the hourly varieties of intensity created and devoured by the different segments of the smaller scale lattice in a three-day time period. The all out essential burden, stockpiling limit and SOC of the battery is appeared in the primary area of the figure for example 16(a). The ages from $\mathrm{PV}$ are appeared in 16(b). Here, for this time span, we can see that the ages from the sustainable sources can serve the heaps and can keep up the SOC of the battery over $70 \%$.

The overall optimization results system configurations and cost components are analyzed in table 3 is micro grid is connected to without grid and table 4 is with grid connection. The systems rankings also given in the corresponding tables.

The battery unit has a significant job in an AC micro grid framework which is fueled by irregular sources. The different insights of the $31 \mathrm{~kW} \mathrm{~h}$ lead corrosive batteries is given in Table 7. As per the recurrence of its usage, the normal existence of the battery is determined to associate with 6-7 years. Fig. 15 gives the normal condition of charge of the battery unit for every long stretch of the year. From this figure, the SOC of the battery is all around kept up inside its predetermined restriction of $60-90 \%$. Most extreme use of battery is found in the long stretches of February to June.

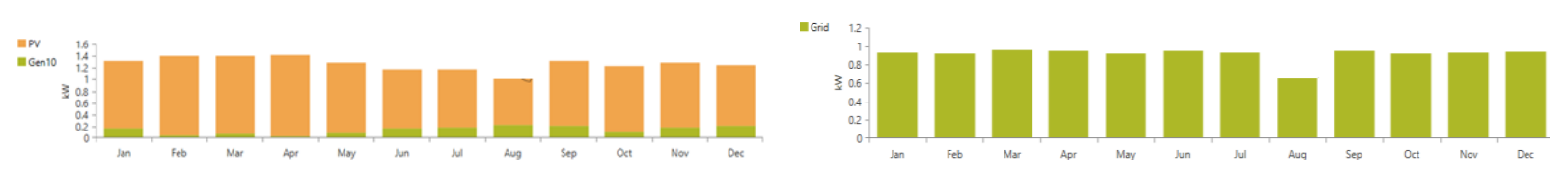

Fig 6. (a) Electrical power production without grid (b) Electrical power production without

grid

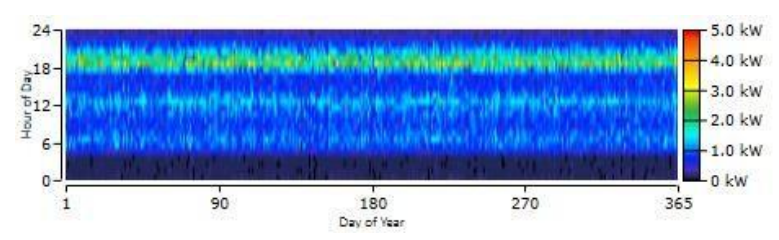

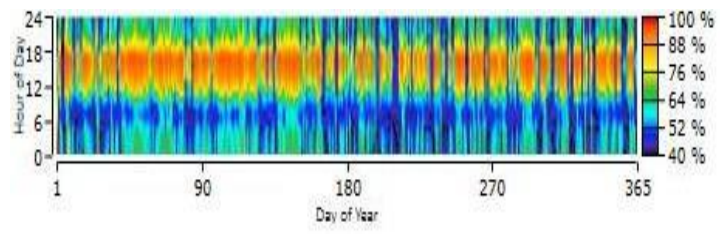

Fig 7. Electrical Energy purchased from the grid Fig 8. Battery state of charge

for without grid connection

system 
Table 3 total optimization results of the micro grid without grid

\begin{tabular}{|c|c|c|c|c|c|c|c|c|c|}
\hline \multirow[t]{2}{*}{ S.No } & \multicolumn{5}{|c|}{ System design } & \multicolumn{4}{|l|}{ Cost } \\
\hline & $\begin{array}{l}\mathrm{PV} \\
\mathrm{KW}\end{array}$ & $\begin{array}{l}\text { Wind } \\
\text { Turbine } \\
\text { G } 3 \mathrm{~kW}\end{array}$ & $\begin{array}{l}\text { Diesel } \\
\text { Generator }\end{array}$ & $\begin{array}{l}\text { Battery } \\
1 \mathrm{kWhLA}\end{array}$ & $\begin{array}{l}\text { Converter } \\
\mathrm{kW}\end{array}$ & $\mathrm{COE}$ & NPC & $\begin{array}{l}\text { Operating } \\
\text { cost }\end{array}$ & $\begin{array}{l}\text { Initial } \\
\text { cost }\end{array}$ \\
\hline 1 & 6.22 & 0 & 10 & 31 & 3.73 & $\$ 0.627$ & $\$ 66,565$ & $\$ 2,512$ & $\$ 34,090$ \\
\hline 2 & 5.65 & 1 & 10 & 31 & 3.74 & $\$ 0.790$ & $\$ 83,923$ & $\$ 2,594$ & $\$ 50,387$ \\
\hline 3 & 14.9 & 0 & 0 & 67 & 4.49 & $\$ 0.834$ & $\$ 88,503$ & $\$ 1,867$ & $\$ 64,256$ \\
\hline 4 & 0 & 0 & 10 & 47 & 3.76 & $\$ 1.01$ & $\$ 107,201$ & $\$ 6,728$ & $\$ 20,228$ \\
\hline 5 & 14.2 & 1 & 0 & 61 & 4.30 & $\$ 1.03$ & $\$ 109,303$ & $\$ 2,594$ & $\$ 80,325$ \\
\hline 6 & 0 & 1 & 10 & 46 & 3.93 & $\$ 1.13$ & $\$ 119,717$ & $\$ 6,323$ & $\$ 37,980$ \\
\hline 7 & 14.7 & 0 & 10 & 0 & 3.76 & $\$ 1.97$ & $\$ 209,179$ & $\$ 12,302$ & $\$ 50,145$ \\
\hline 8 & 0 & 0 & 10 & 0 & 3.69 & $\$ 2.00$ & $\$ 212,030$ & $\$ 15,929$ & $\$ 6,106$ \\
\hline 9 & 13.6 & 1 & 10 & 0 & 3.76 & $\$ 2.13$ & $\$ 226,367$ & $\$ 12,478$ & $\$ 65060$ \\
\hline 10 & 0 & 1 & 10 & 0 & 3.64 & $\$ 2.19$ & $\$ 223,014$ & $\$ 16,161$ & $\$ 24,092$ \\
\hline
\end{tabular}

Table 4 total optimization results of the micro grid with grid

\begin{tabular}{|c|c|c|c|c|c|c|c|c|c|}
\hline \multirow[t]{2}{*}{ S.No } & \multicolumn{5}{|c|}{ System design } & \multicolumn{4}{|l|}{ cost } \\
\hline & $\begin{array}{l}\mathrm{PV} \\
\mathrm{kW}\end{array}$ & $\begin{array}{l}\text { Wind } \\
\text { Turbine } \\
\text { G3 kW }\end{array}$ & $\begin{array}{l}\text { Diesel } \\
\text { Generator }\end{array}$ & $\begin{array}{l}\text { Grid } \\
\mathrm{kW}\end{array}$ & $\begin{array}{l}\text { Converter } \\
\mathrm{kW}\end{array}$ & $\mathrm{COE}$ & NPC & $\begin{array}{l}\text { Operating } \\
\text { cost }\end{array}$ & $\begin{array}{l}\text { Initial } \\
\text { cost }\end{array}$ \\
\hline 1 & 0 & 0 & 0 & 999,999 & 0 & $\$ 0.100$ & $\$ 10,624$ & $\$ 821.82$ & 0 \\
\hline 2 & 0.00596 & 0 & 0 & 999,999 & 0.004 & $\$ 0.100$ & $\$ 10,633$ & $\$ 821.01$ & $\$ 19.31$ \\
\hline 3 & 0 & 0 & 0 & 999,999 & 0.020 & $\$ 0.106$ & $\$ 11,291$ & $\$ 849.71$ & $\$ 306.25$ \\
\hline 4 & 0.120 & 0 & 0 & 999,999 & 0.020 & $\$ 0.109$ & $\$ 11,567$ & $\$ 843.28$ & $\$ 665.63$ \\
\hline 5 & 0 & 0 & 10 & 999,999 & 0.001 & $\$ 0.136$ & $\$ 14,457$ & $\$ 731.49$ & $\$ 5000$ \\
\hline 6 & 0.00372 & 0 & 10 & 999,999 & 0.007 & $\$ 0.136$ & $\$ 14,464$ & $\$ 731.01$ & $\$ 5013$ \\
\hline 7 & 0 & 0 & 10 & 999,999 & 0.001 & $\$ 0.142$ & $\$ 15,115$ & $\$ 759.22$ & $\$ 5300$ \\
\hline 8 & 0.0243 & 0 & 10 & 999,999 & 0.014 & $\$ 0.143$ & $\$ 15,151$ & $\$ 756.10$ & $\$ 5377$ \\
\hline 9 & 0 & 1 & 0 & 999,999 & 0 & $\$ 0.297$ & $\$ 32,117$ & $\$ 1092$ & $\$ 18000$ \\
\hline 10 & 0.479 & 1 & 0 & 999,999 & 0.083 & $\$ 0.313$ & $\$ 33,924$ & $\$ 1095$ & $\$ 19763$ \\
\hline
\end{tabular}

\section{CONCLUSION}

The paper investigation the sizing and rankings of $\mathrm{AC}$ micro grids for with and without grid connections. The results give a very clear in the table 3 and 4, each system components and for each system setup the cost of energy. The grid connected micro grid investment is low and without connection of micro grid is investment is high but conventional source are running out that's why it has to go for renewable energy sources. The cost of economy COE is for grid connected is $\$ 0.100$ per unit and without grid connected system of COE is $\$ 0.627$ per unit. When comparing the two systems without grid connection is little bit high but it not issues for increasing of utility of renewable energy sources.

\section{REFERENCES}

1. Chowdhury S, Chowdhury Sp, Crossley P. Microgrids And Active Distribution Networks. Stevenage: Institution Of Engineering And Technology; 2009.

2. Lopes Jap, Madureira Ag, Moreira Cclm. A View Of Microgrids. Wiley Interdiscip Rev: Energy Environ 2013;2:86-103.

3. Lidula Nwa, Rajapakse Ad. Microgrids Research: A Review Of Experimental Microgrids And Test Systems. Renew Sustain Energy Rev 2011;15:186-202.

4. Jenkins N, Ekanayake Jb, Strbac G. Distributed Generation. London: Institution Of Engineering And Technology; 2010.

5. Lasseter Rh, Paigi P. Microgrid: A Conceptual Solution. Ieee 35th Annual Power Electronics Specialists Conference, 4285; 2004. 
6. Bhaskara Sn, Chowdhury Bh. Microgrids - A Review Of Modeling, Control, Protection, Simulation And Future Potential. 2012 Ieee Power \& Energy Society General Meeting. 1; 2012.

7. Llc He. Homer. 〈Http://Wwwhomerenergycom//, 2015 [Accessed 21 February 2015].

8. Sen R, Bhattacharyya Sc. Off-Grid Electricity Generation With Renewable Energy Technologies In India: An Application Of Homer. Renew Energy 2014;62:388-98.

9. Kumar Yvp, Bhimasingu R. Optimal Sizing Of Microgrid For An Urban Community Building In South India Using Homer. Power Electronics, Drives And Energy Systems (Pedes), 2014 Ieee International Conference On 2014. P. 1-6.

10. Hafez O, Bhattacharya K. Optimal Planning And Design Of A Renewable Energy Based Supply System For Microgrids. Renew Energy 2012;45:7-15.

11. Hurtt J, Jhirad D, Lewis J. Solar Resource Model For Rural Microgrids In India. Pes General Meeting | Conference \& Exposition; 2014ieee2014. P. 1-5.

12. Kim I, James J-A, Crittenden J. The Case Study Of Combined Cooling Heat And Powerand Photovoltaic Systems For Building Customers Using Homer Software. Electr Power Syst Res 2017;143:490-502.

13. Amutha Wm, Rajini V. Cost Benefit And Technical Analysis Of Rural Electrification Alternatives In Southern India Using Homer. Renew Sustain Energy Rev 2016;62:236-46.

14. Singh S, Singh M, Kaushik Sc. Feasibility Study Of An Islanded Microgrid In Rural Area Consisting Of Pv, Wind, Biomass And Battery Energy Storage System. Energy Convers Manag 2016;128:178-90.

15. Castellanos Jg, Walker M, Poggio D, Pourkashanian M, Nimmo W. Modelling An Off- Grid Integrated Renewable Energy System For Rural Electrification In India Using Photovoltaics And Anaerobic Digestion. Renew Energy 2015;74:390-8.

16. Azaza M, Wallin F. Multi Objective Particle Swarm Optimization Of Hybrid Microgrid System: A Case Study In Sweden. Energy 2017;123:108-18.

17. Sachs J, Sawodny O. Multi-Objective Three Stage Design Optimization For Island Microgrids. Appl Energy 2016;165:789-800.

18. Sen R, Bhattacharyya Sc. Off-Grid Electricity Generation With Renewable Energy Technologies In India: An Application Of Homer. Renew Energy 2014;62:388-98.

19. Thomas D, Deblecker O, Ioakimidis Cs. Optimal Design And Techno-Economic Analysis Of An Autonomous Small Isolated Microgrid Aiming At High Res Penetration. Energy 2016;116:364-79.

20. Okoye Co, Solyali O. Optimal Sizing Of Stand-Alone Photovoltaic Systems In Residential Buildings. Energy 2017;126:573-84.

21. Bhattarai Pr, Thompson S. Optimizing An Off-Grid Electrical System In Brochet, Manitoba, Canada. Renew Sustain Energy Rev 2016;53:709-19.

22. Al Busaidi As, Kazem Ha, Al-Badi Ah, Farooq Khan M. A Review Of Optimum Sizing Of Hybrid PvWind Renewable Energy Systems In Oman. Renew Sustain Energy Rev2016;53:185-93.

23. Shahzad Mk, Zahid A, Ur Rashid T, Rehan Ma, Ali M, Ahmad M. Techno-Economic Feasibility Analysis Of A Solar-Biomass Off Grid System For The Electrification Of Remote Rural Areas In Pakistan Using Homer Software. Renew Energy.

24. Chitaranjan Phurailatpam, Bharat Singh Rajpurohit, Lingfeng Wang Planning And Optimization Of Autonomous De Microgrids For Rural And Urban Applications In India Renewable And Sustainable Energy Reviews; 201782 (2018) 194-204.

25. Dhawale, Aw, And Anshuman C. Pemgirikar. "Comparative Study Of Cost And Duration Related To Night Time And Day Time Construction Of Flyover Project." International Journal Of Civil Engineering (Ijce) $5.2(2016) 1-8$

26. Kadam, Shweta, And Shrikant Charhate. "Some Studies On Cost Overrun Factors Affecting Repairs And Rehabilitation Of Buildings." 5.6 (2016): 51-56.

27. Sow, G. Bop D. "Study Of The Energy Behavior Of Different Refrigerants: Energy Cost And Environmental Impact." International Journal Of Applied And Natural Sciences (Ijans) 7.6 (2018) 1-8

28. Munyoro, Gerald, Freddy Chimbari, And Fanuel Tinashe Chirimba. "The Cost Of Indigenous Banks To The Zimbabwean Economy: A Case Study Of Harare." Impact: International Journal Of Research In Business Management (Impact: Ijrbm) 5.12 (2017) 81-94

29. Pi, Vu Ngoc, Et Al. "Cost Optimization Study Of Two-Step Helical Gearboxes With First Stage Double Gear Sets." International Journal Of Mechanical And Production Engineering Research And Development (Ijmperd) 10.3 (2020) 573-584

30. Alrobaian, Abdulrahman A., Et Al. "A New Approach To Low-Cost Open-Typed Subsonic Compressible Flow Wind Tunnel For Academic Purpose." International Journal Of Mechanical And Production (Ijmperd) 8.6 (2018): 383-394. 